\title{
Posters
}

\section{e Top Posters Selected for 2017 19th Annual ASIPP Meeting}

\author{
First Place Abstract Presentation \\ Dr. Richard North \\ Multicolumn Spinal Cord Stimulation for Predominant Back Pain in Failed Back Surgery \\ Syndrom Patients: An International Multicenter Randomized Trial (PROMISE Study) \\ $2^{\text {nd }}$ Place Abstract Presentation \\ Gladstone C. McDowell, II MD \\ Effectiveness and Safety of Intrathecal Ziconotide as teh First Agent in Pump for Adult \\ Patients with Severe Chronic Pain \\ Fellow Award \\ Christian Estrada \\ Performing a Transforaminal Epidural in a Patient with an Implanted DRG Nerve \\ Stimulator \\ Resident Award \\ Ken Ehrhardt \\ New Treatment of Lower Back Pain with Matrix Metalloproteinases
}




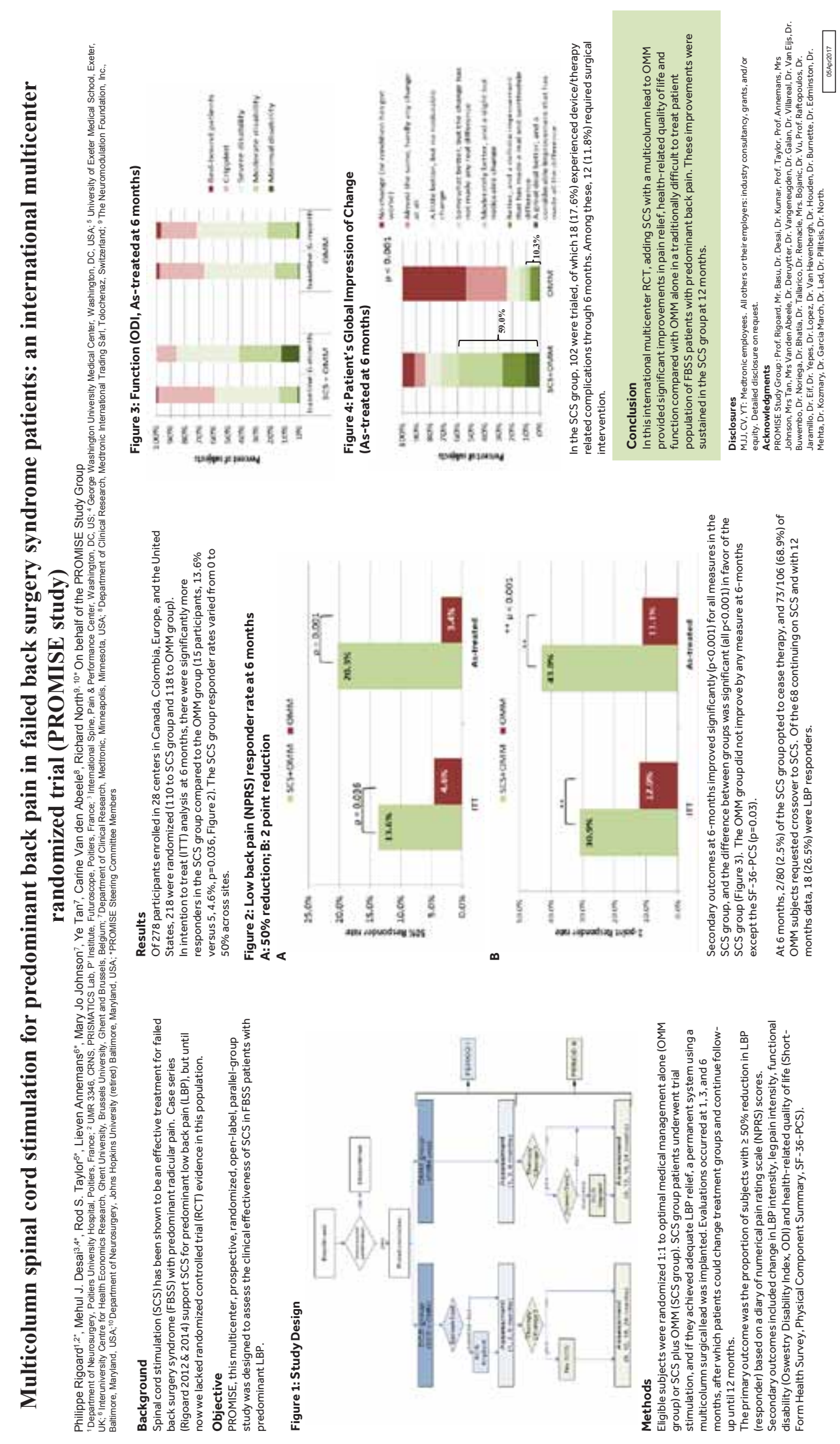




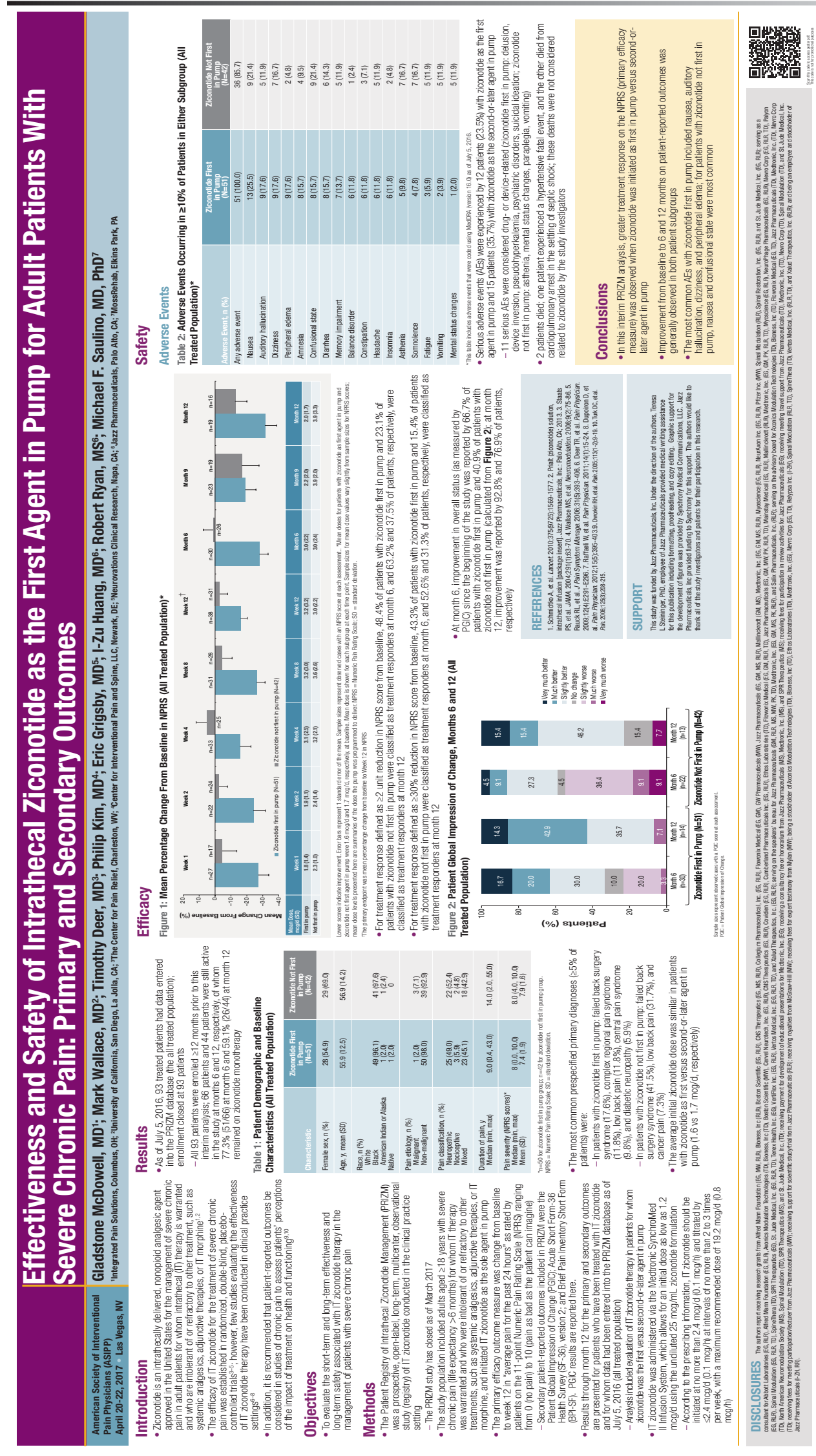

www.painphysicianjournal.com 


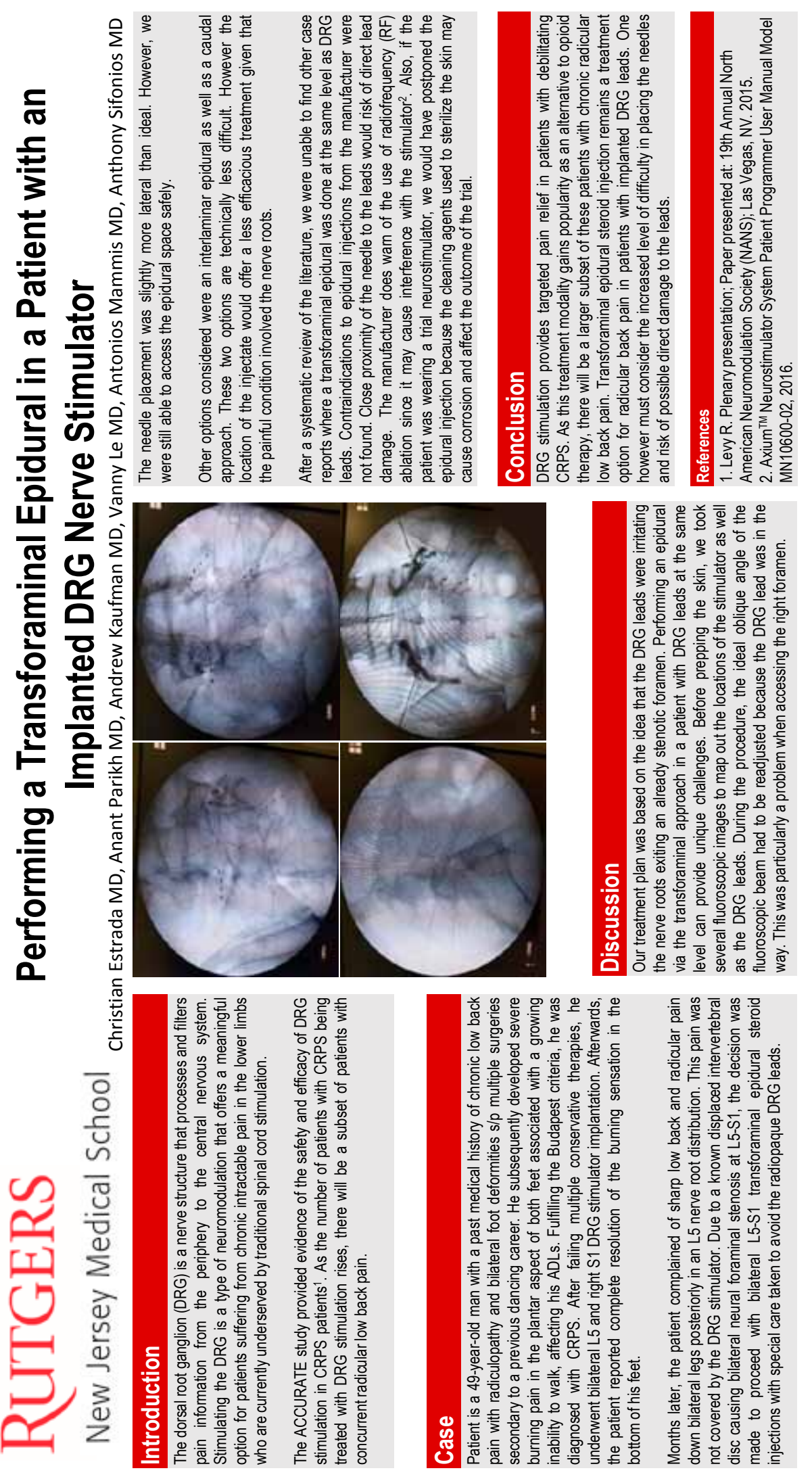



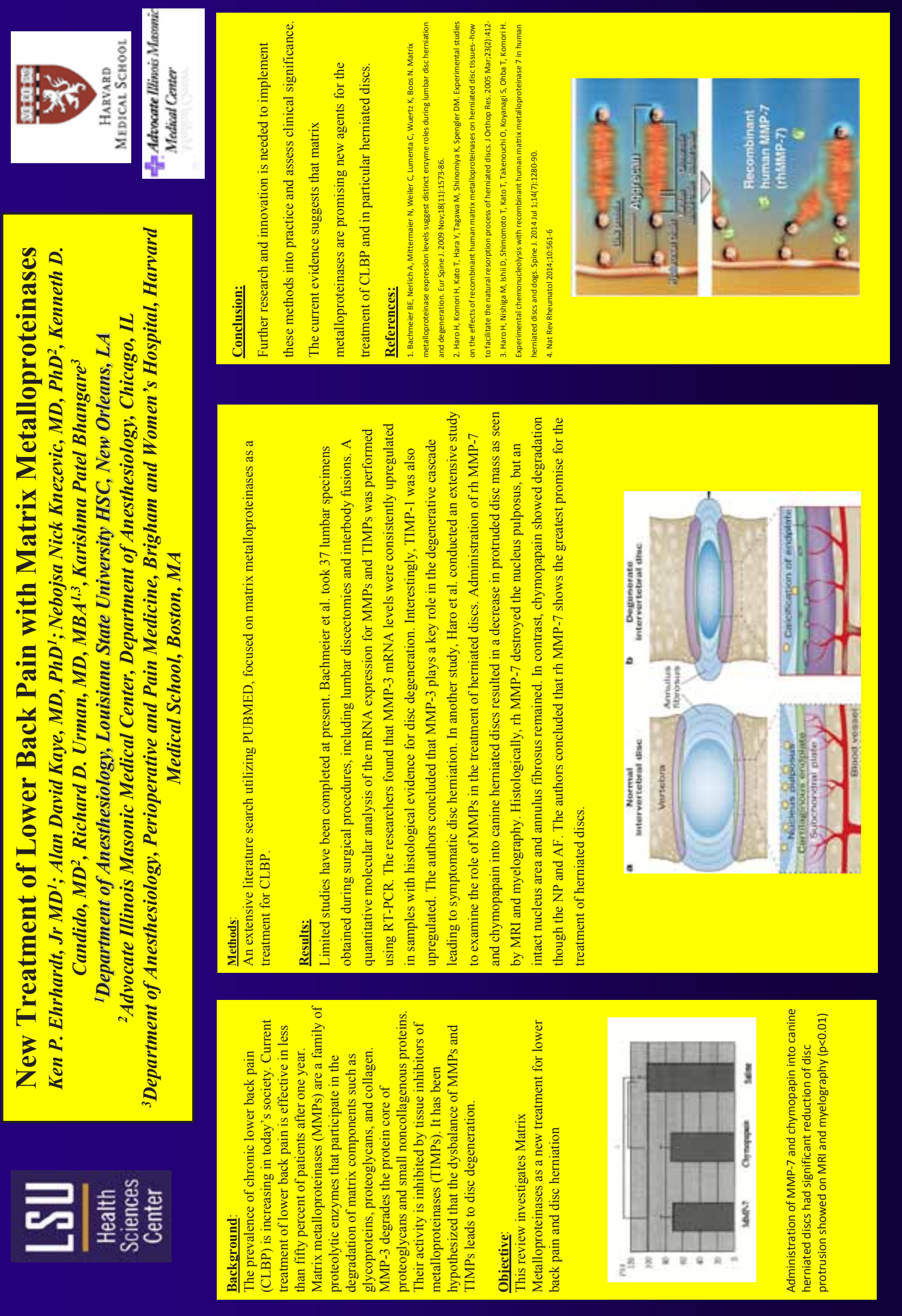

www.painphysicianjournal.com 
Pain Physician: May/June 2017: 20:E613-E632

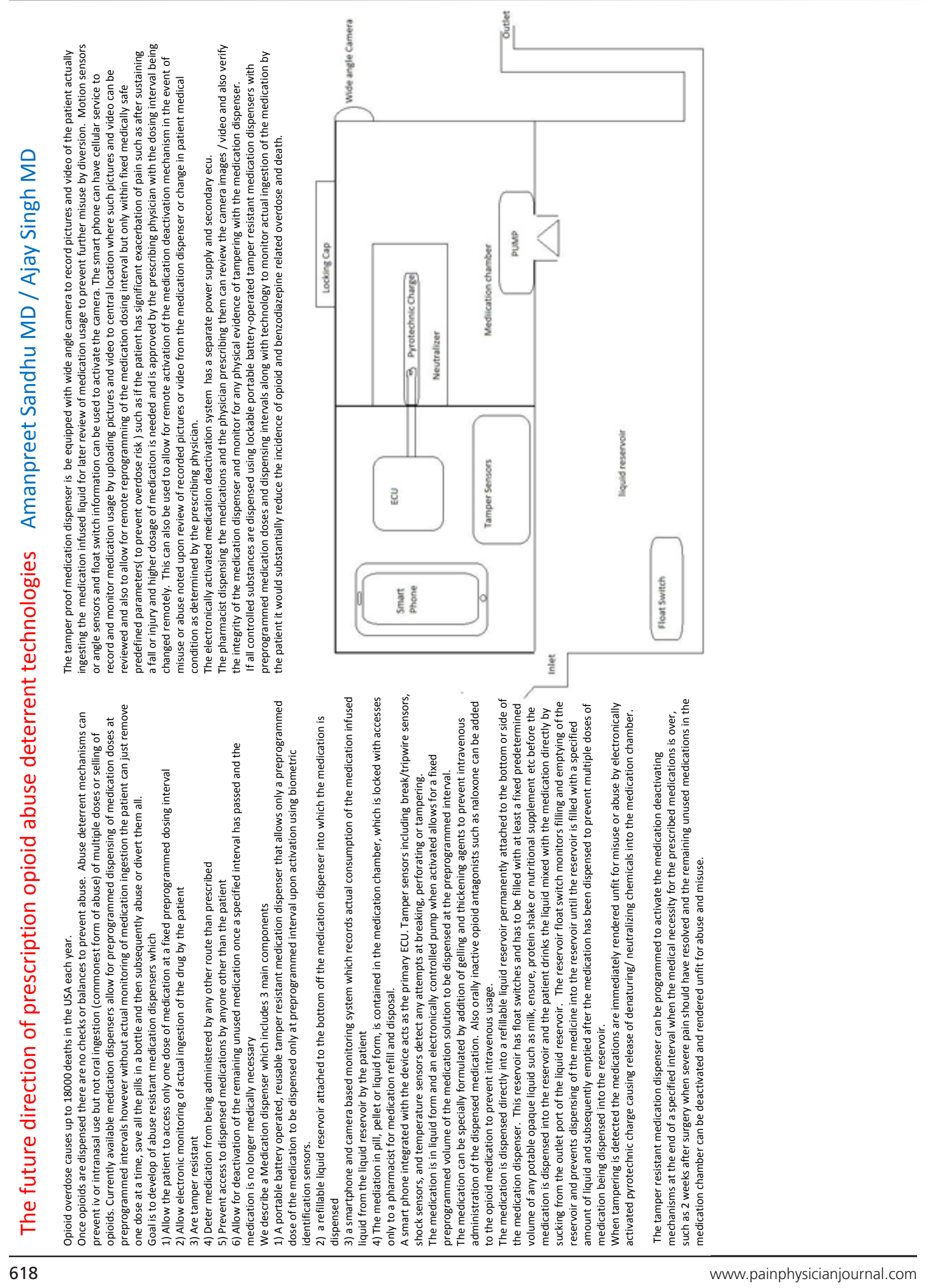




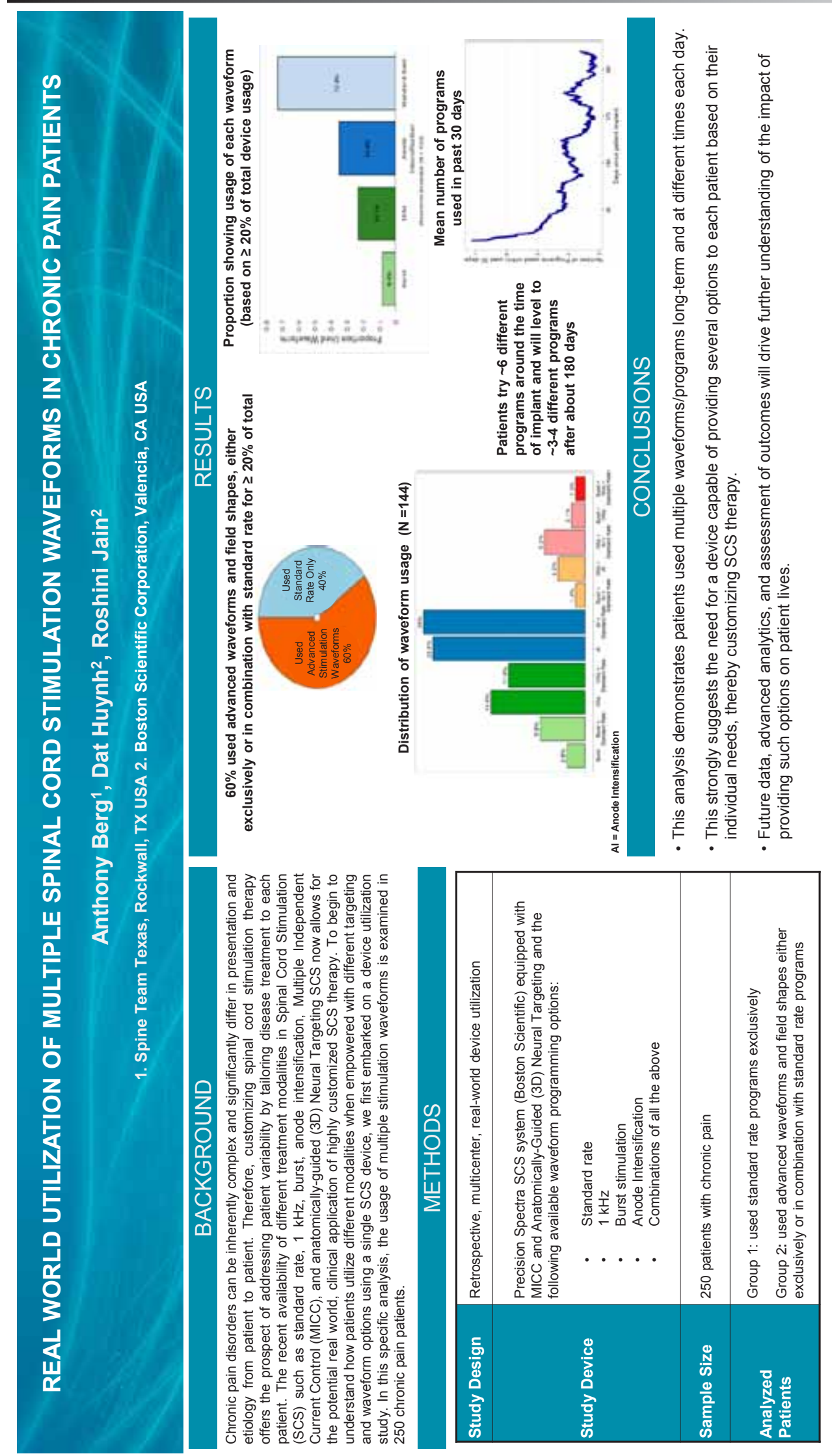




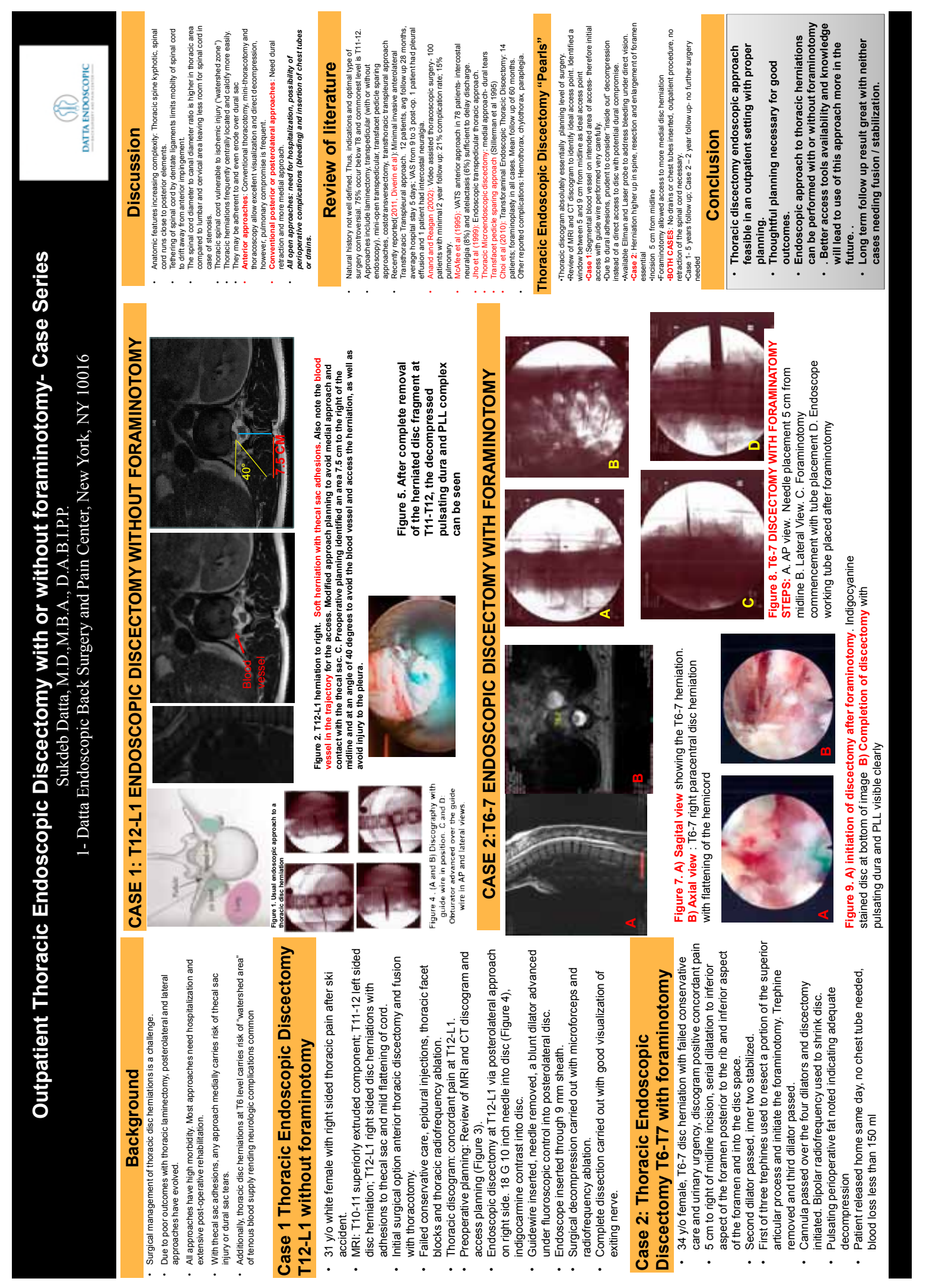


Top Posters 2017
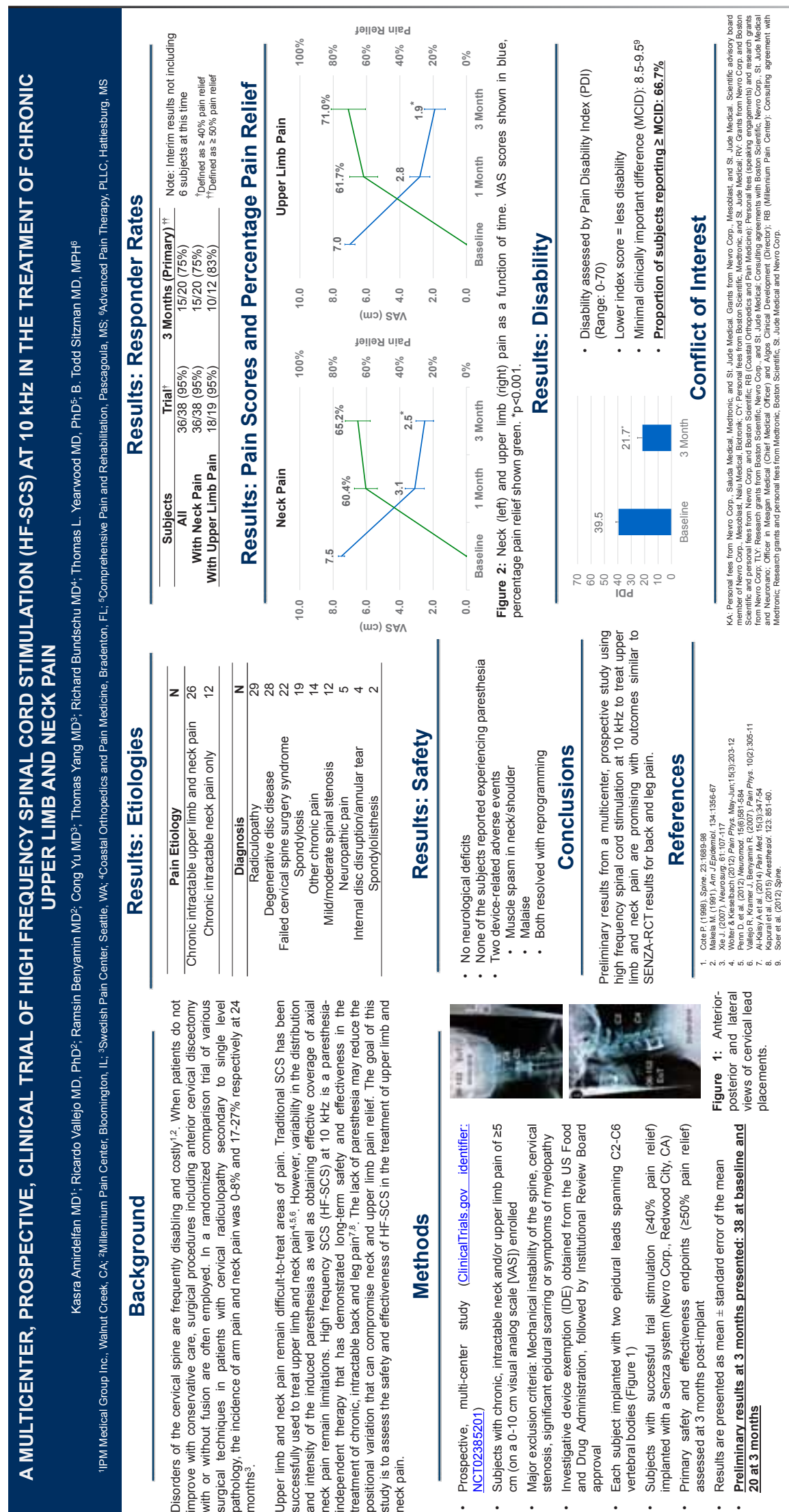


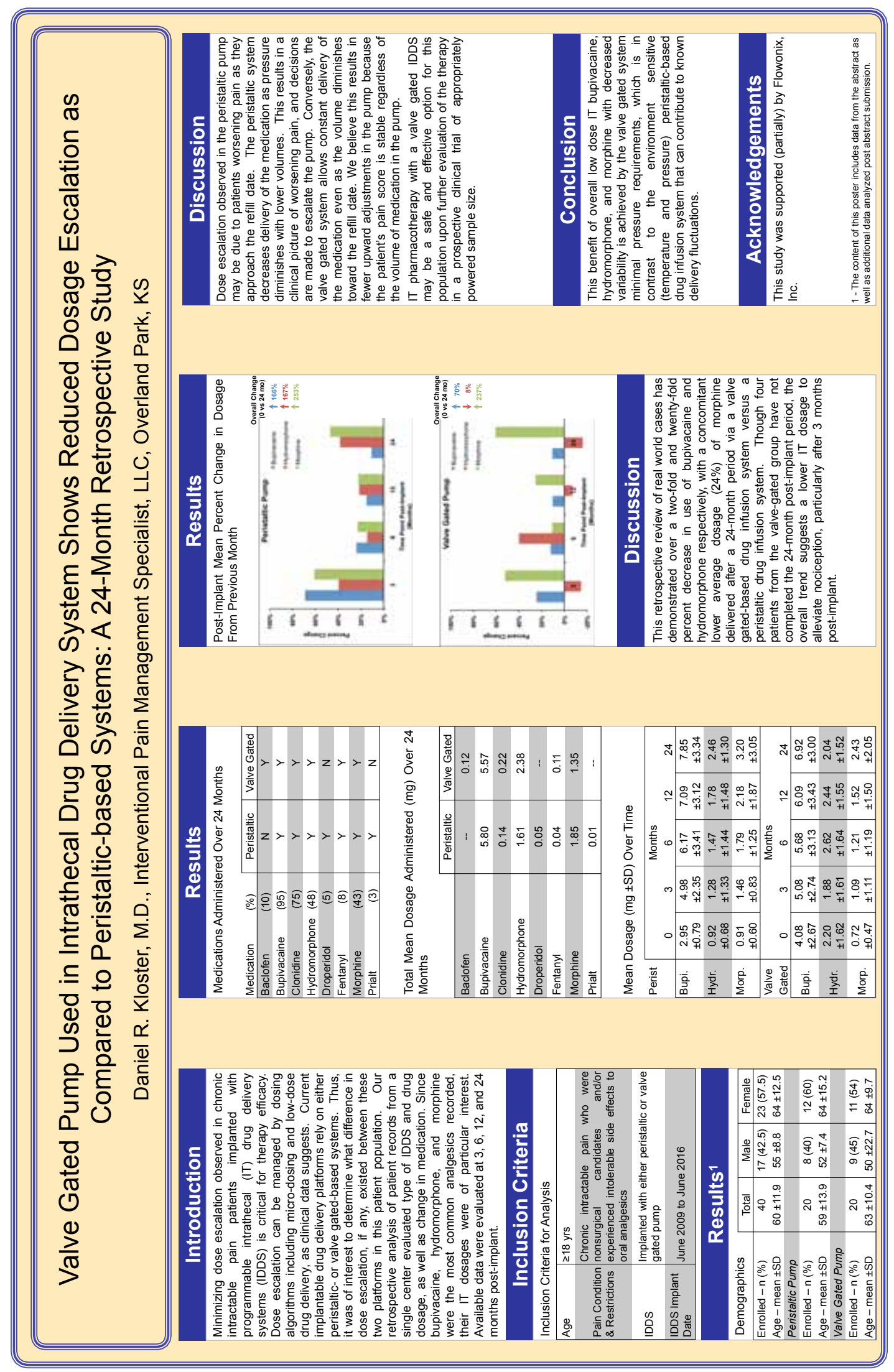




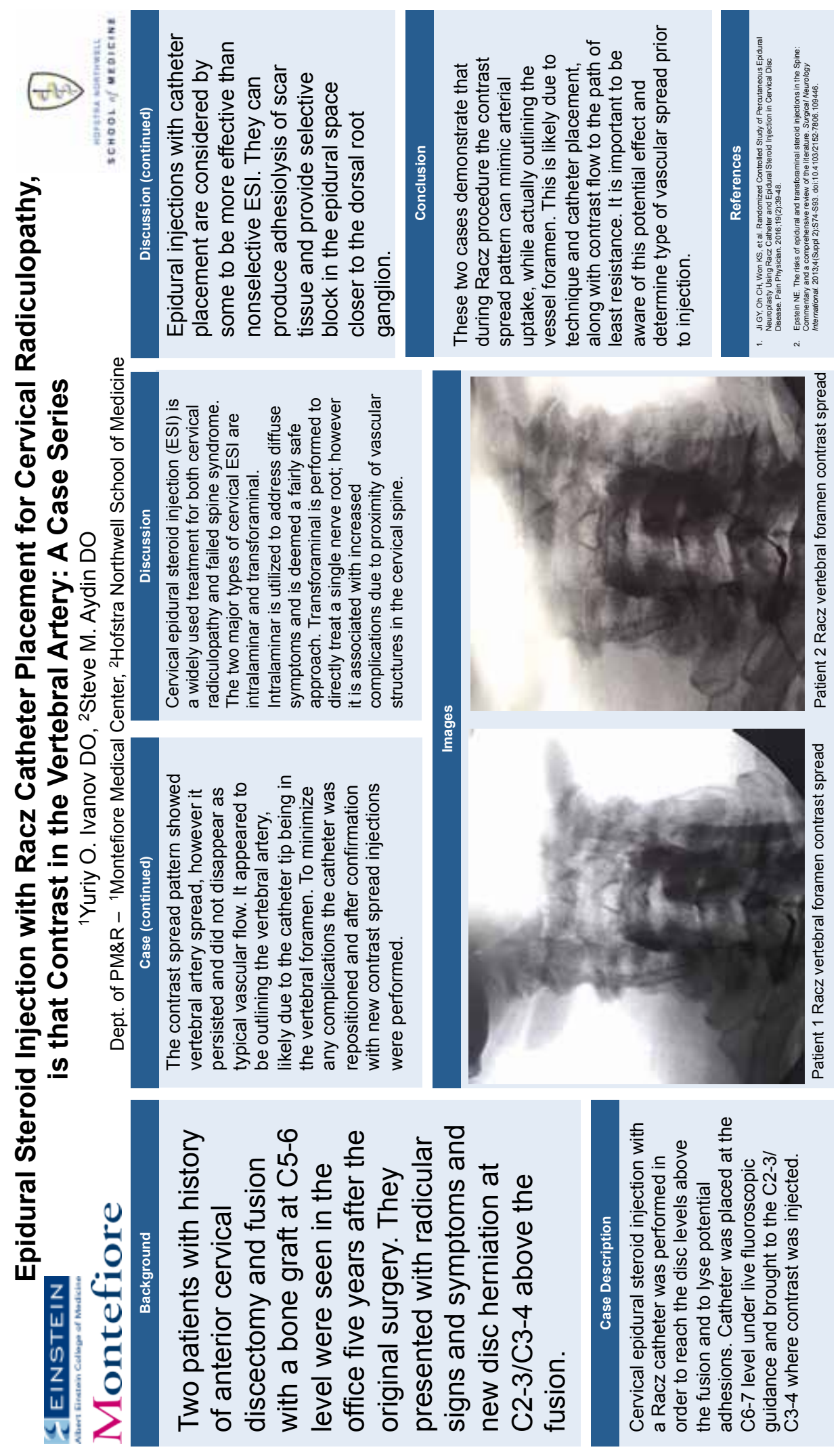


Pain Physician: May/June 2017: 20:E613-E632
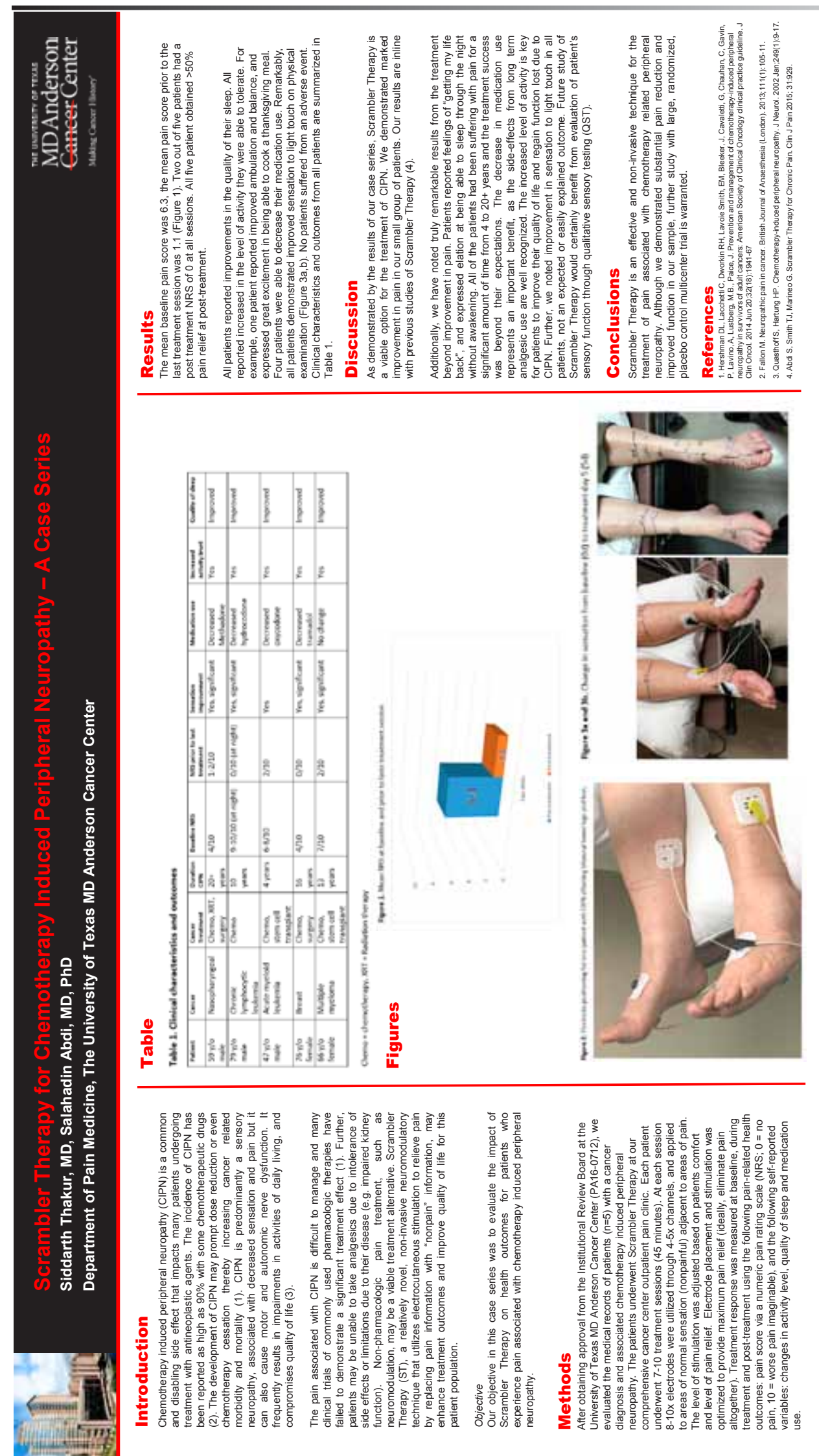


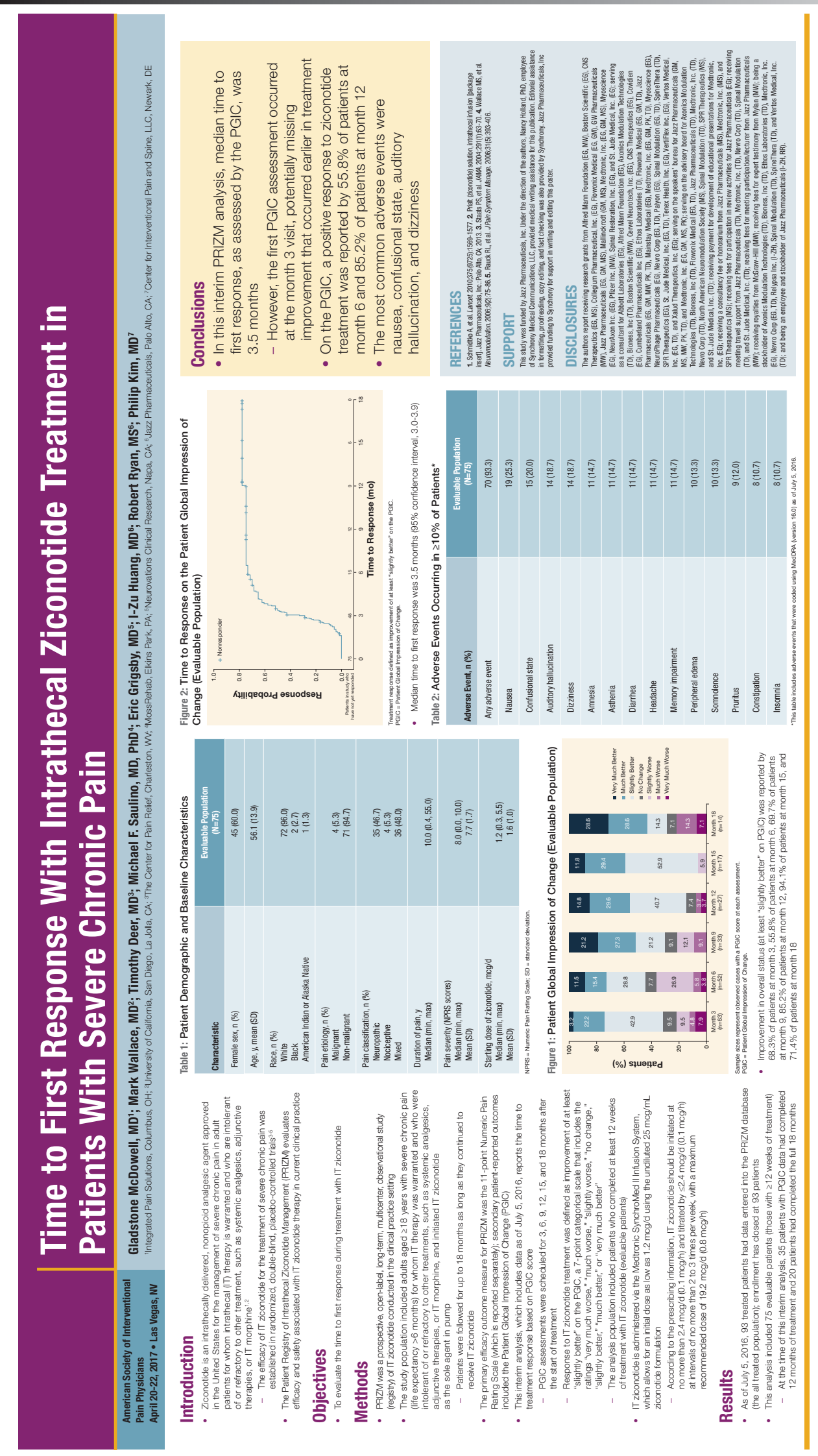

www.painphysicianjournal.com 


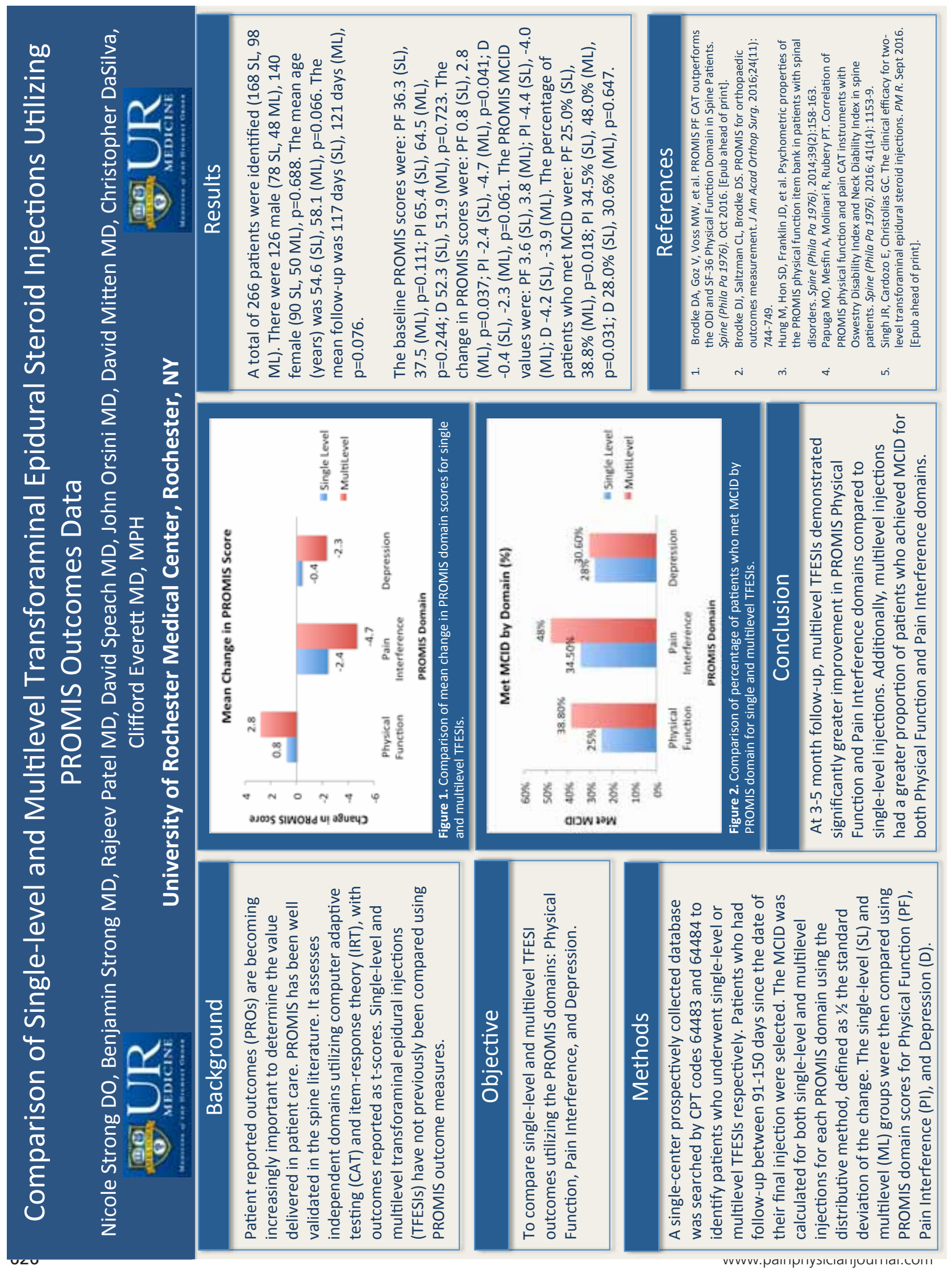




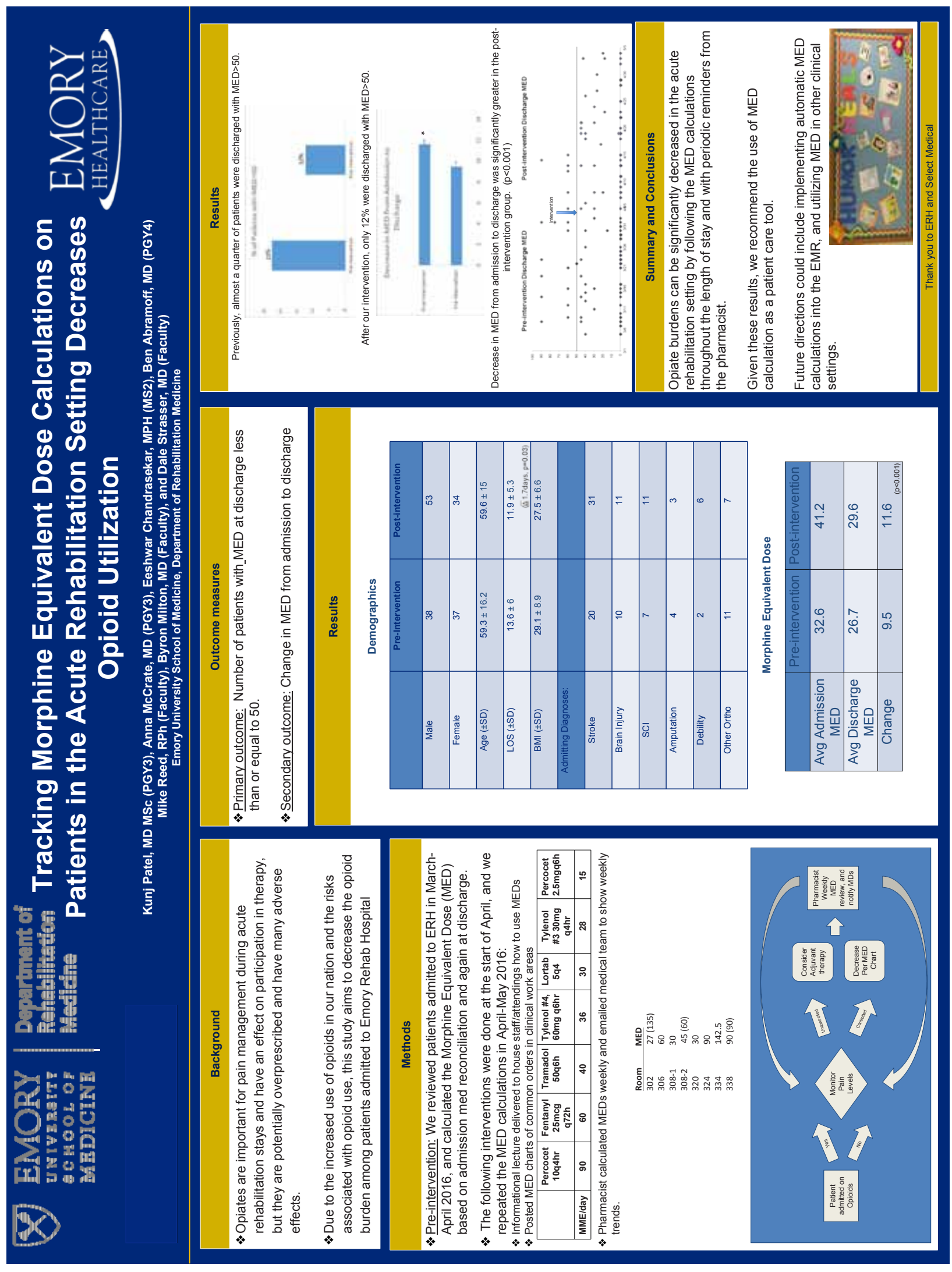

www.painphysicianjournal.com 


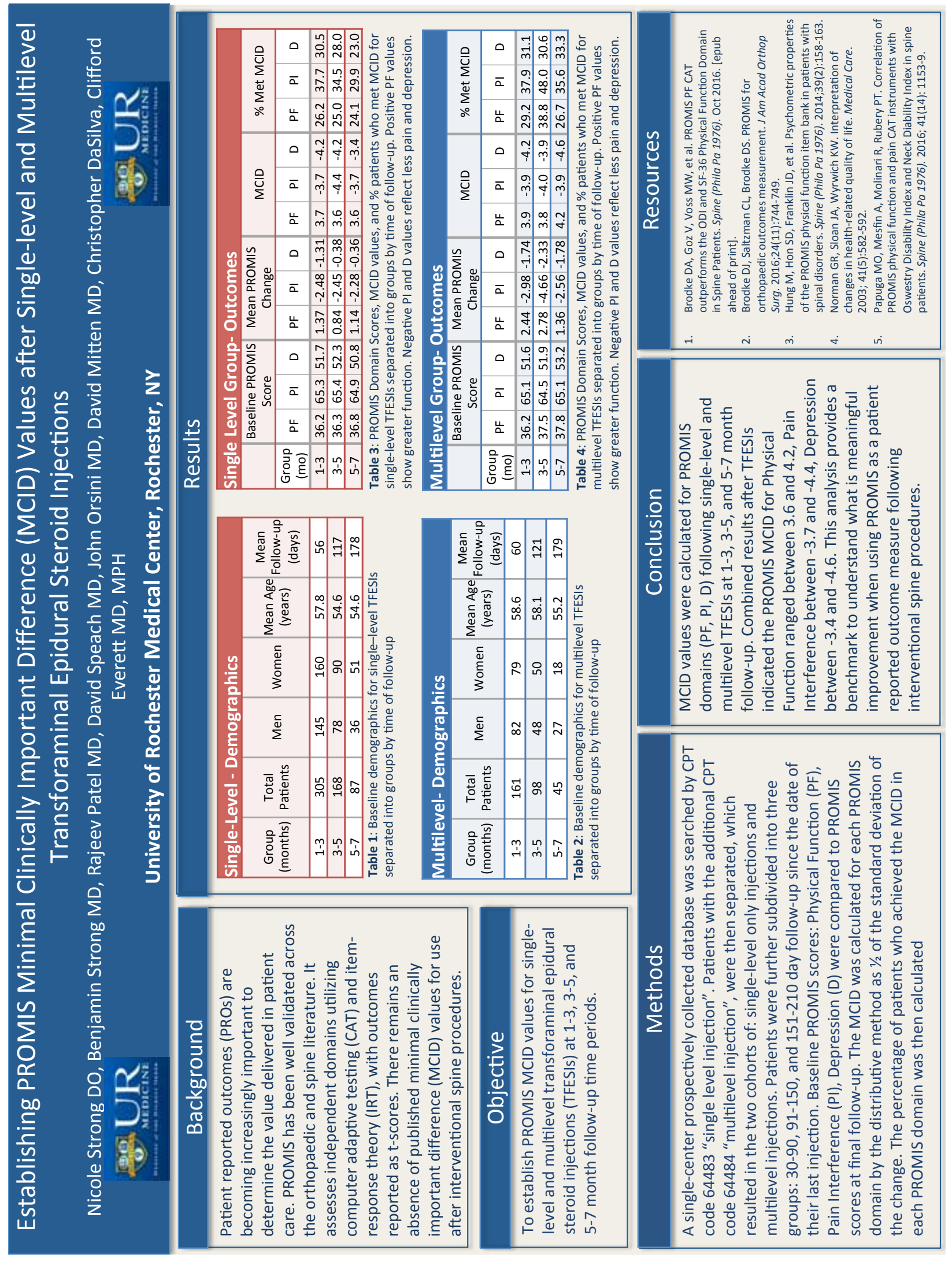




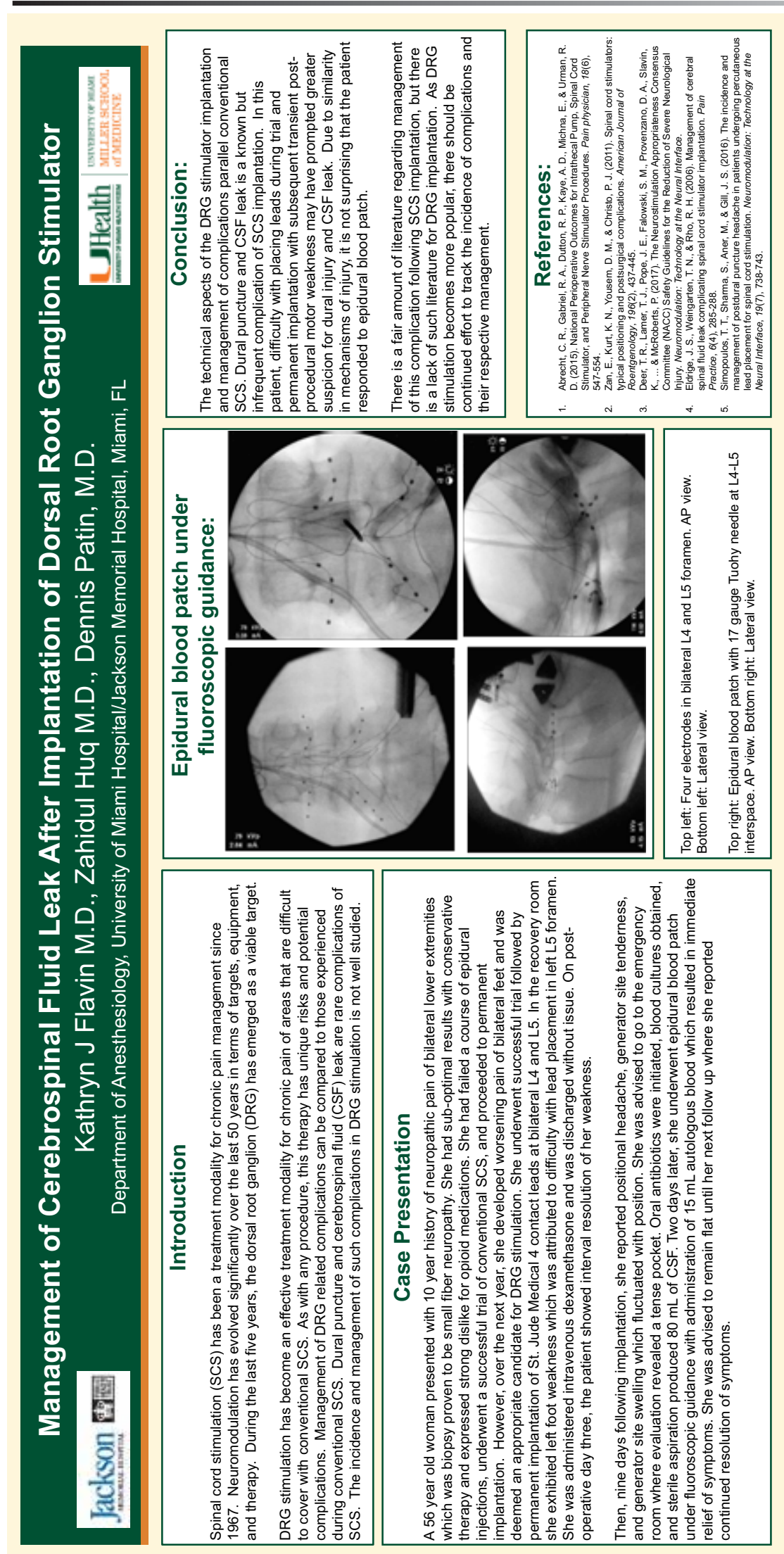

www.painphysicianjournal.com 


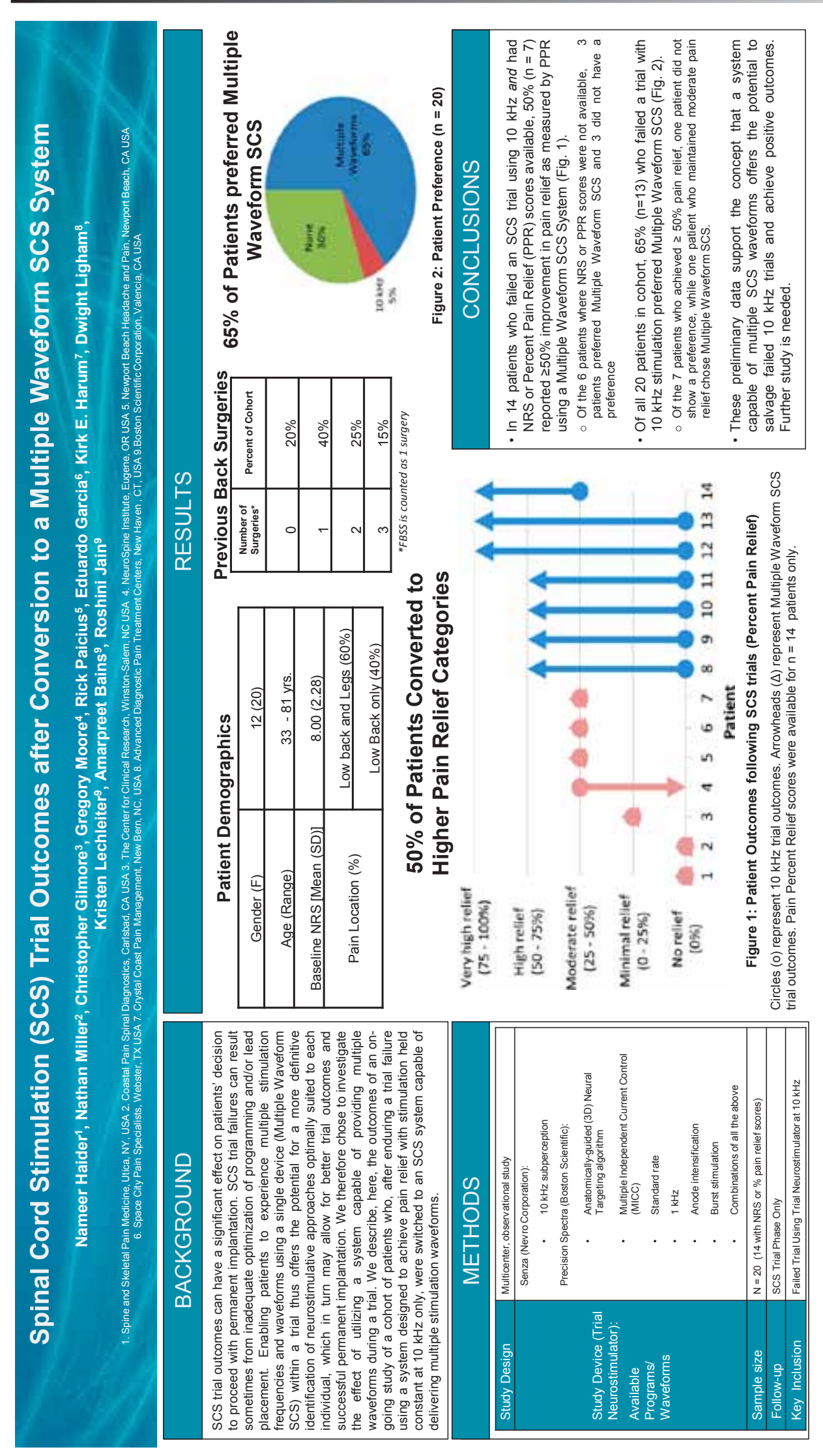




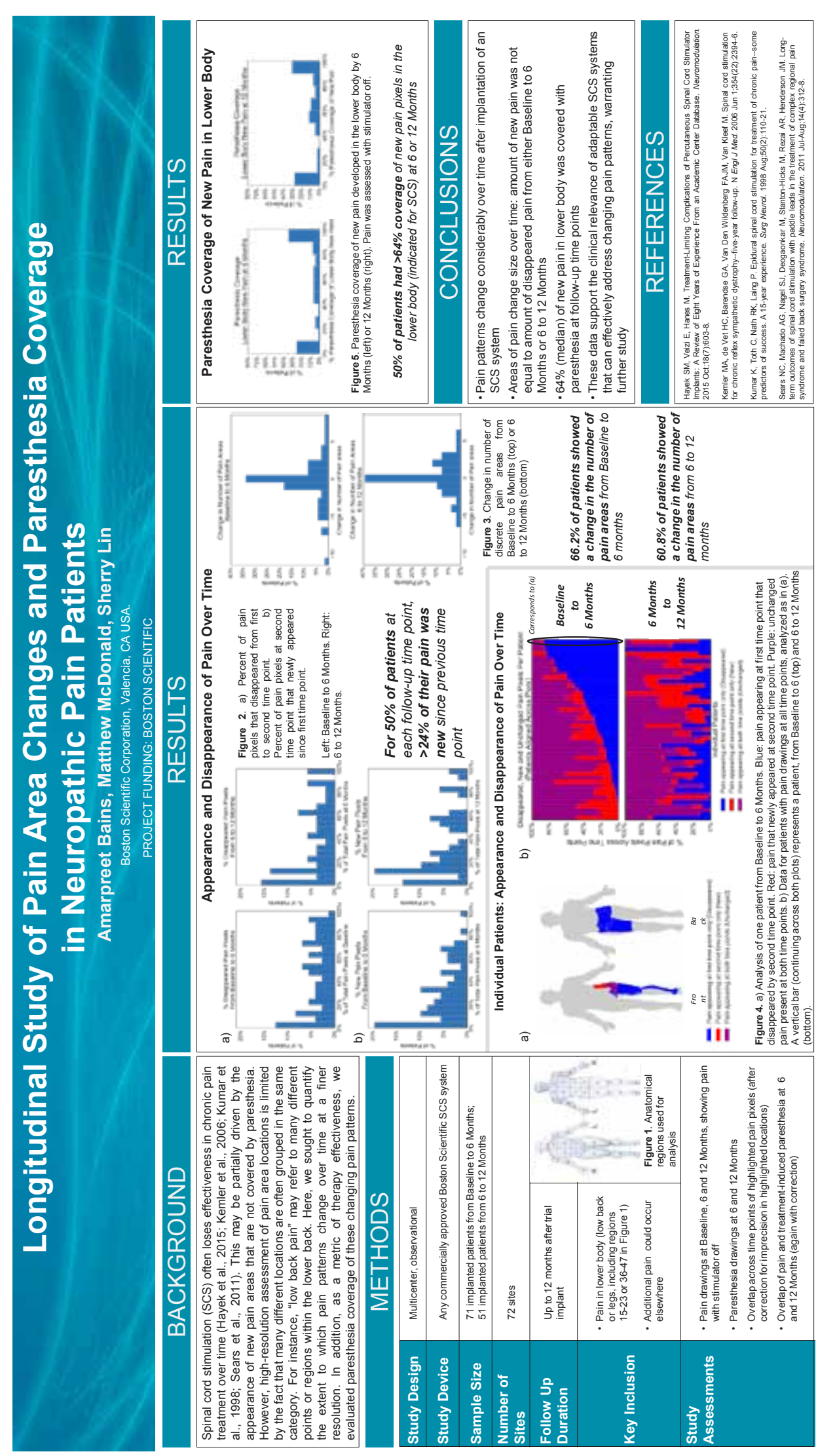




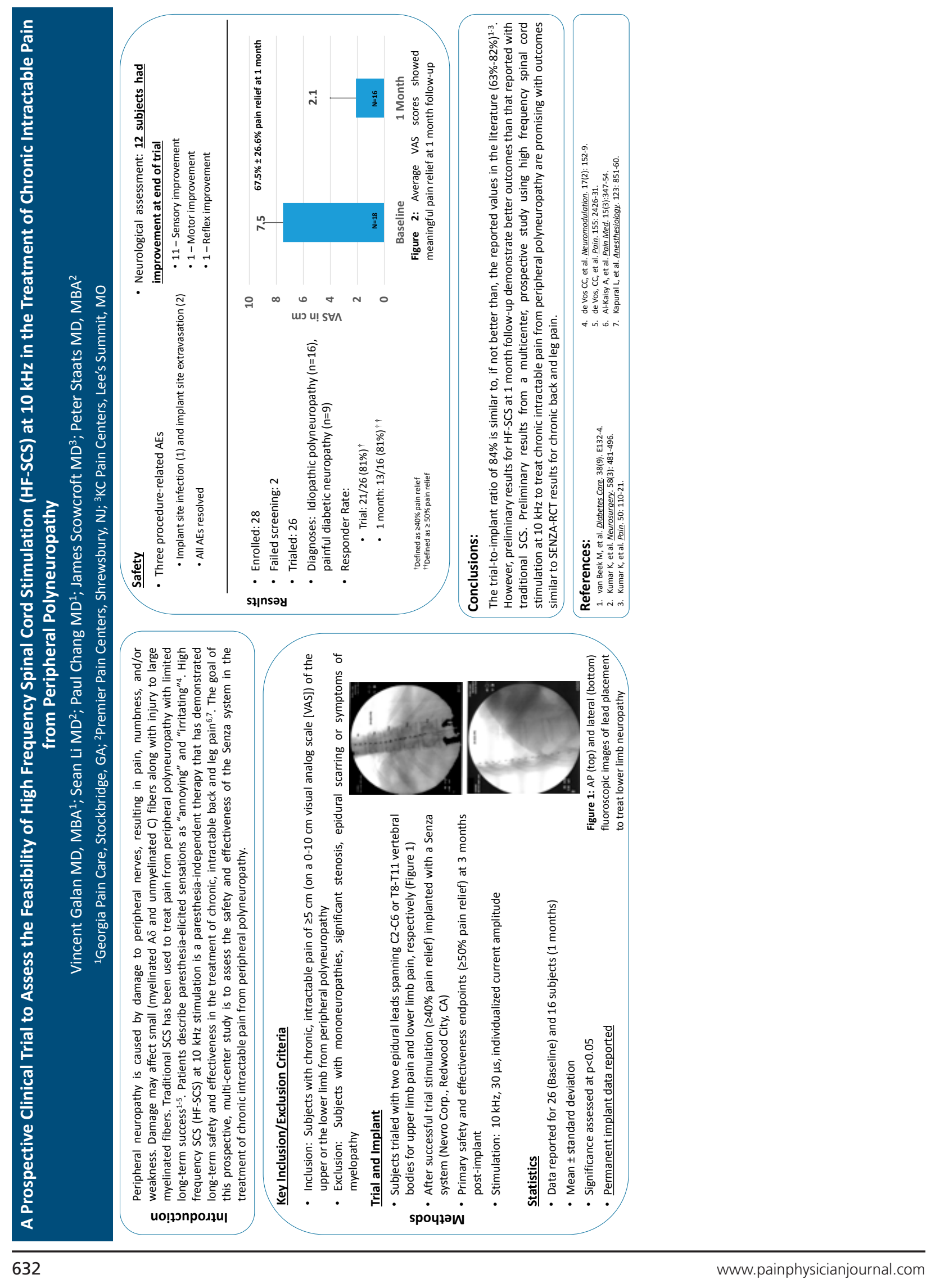

